\title{
Reviewing the Causes in the K-12 period of the Chinese Gender Inequity in Higher Education
}

\author{
Yuexi Liu ${ }^{1, a, \dagger,{ }^{*}}$ Yitong Jin ${ }^{2, b, \dot{\dagger}, *}$ Kaixin $\mathrm{Yu}^{3, \mathrm{c}, \dagger,{ }^{*}}$ Siyi Shen ${ }^{4, \mathrm{~d}, \dagger, *}$ \\ ${ }^{1}$ Shenzhen Vanke Meisha Academy, Shenzhen, Guangdong, 518054, China \\ ${ }^{2}$ High School Affiliated to Shanghai Jiao Tong University IB Centre, Shanghai, Shanghai, 200000, China \\ ${ }^{3}$ WLSA Shanghai Academy, Shanghai, Shanghai, 200122, China \\ ${ }^{4}$ Xiamen University Malaysia, Chengdu, Sichuan, 610000, China

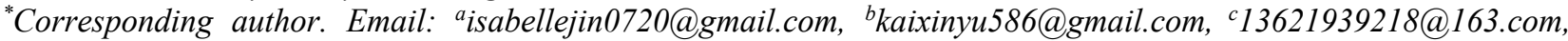 \\ ${ }^{d}$ EGE2009268@xmu.edu.my. \\ these authors contributed equally.
}

\begin{abstract}
This paper aimed to investigate the main reasons for gender inequity problems in the K-12 period and raise attention among schools, family and educators. This paper reviews previous work and adds comments and arguments on it. There are four major factors which can cause gender inequity in education: (1) Chinese elementary education textbooks are not beneficial for developing a correct gender idea; (2) the recognition of gender role is affected by relationship among family members, parents' educational methods and attitudes, and family economic conditions; (3) the chance of receiving education is determined by gender norms, financial returns, and insufficiency of political representations. This paper hopes to raise awareness regarding gender inequity in education within society since gender inequity has been neglected for decades and poses possible solutions as well.
\end{abstract}

Keywords: Gender Inequity, K-12 Education, Family, Textbooks, Society, Teachers

\section{INTRODUCTION}

This paper reviews some characteristics of gender inequity in the Chinese K12 educational system. These gender inequity factors will unconsciously affect the students' psychological growth and the shaping of gender equity concepts. There is no doubt that many essays related to Chinese gender inequity issues can be found nowadays. But little attention has been paid to the root causes of Chinese gender inequity, especially in K-12 education. To call people's attention to the gender inequity in K-12 education and arouse their reflection on these phenomena, the authors decided to review the causes in the K-12 period of the Chinese gender inequity in higher education. This literature review studies the causes from four perspectives: textbooks, teachers, family, and social factors. Correspondingly, four main findings are drawn through this literature review.

\section{LITERATURE REVIEW}

\subsection{Textbooks as a Cause of Gender Inequity in K-12 Period in China}

\subsubsection{An Imbalance between the Number of Male Characters and that of Female Characters}

According to many studies, there is an imbalance between the number of male characters and that of female characters in Chinese elementary education textbooks [13]. For instance, the data conducted shows that there are 277 figures in the textbooks of Jiangsu (a province in China) Education Edition, 206 of which are male, accounting for $74.3 \%$ of the total and 71 females, accounting for $25.6 \%$ of the total [4]. There are 175 characters in the texts about characters, of which 90 main male characters, accounting for $86 \%$, and 15 main female characters, accounting for only $14 \%$. However, the California version has a total of 334 people, 185 of whom are men, accounting for $55.3 \%$ of the total, and 149 women, accounting for $44.6 \%$ of the total. There are 96 characters in the character class text, among which 26 are 
mainly male characters, which is about $55 \%$, and 21 are mainly female characters, approximately $45 \%$.

Due to this survey, it is obvious that the number of male and female characters is different. There are usually more male characters than women in Chinese elementary education textbooks. This phenomenon represents Chinese elementary textbooks are potentially delivering a concept of gender inequity to the students. The imbalance between the number of male characters and female characters represents a piece of information that males are more dominant than females, which may cause the gender consciousness has not fully developed teenagers and children have the wrong gender concept. Thus, male students may think that they are superior to others, while female students may think that they are inferior to others and become less confident. Compared with Chinese textbooks, the California version avoids transmitting misconceptions about gender caused by this imbalance as they keep the number of male and female characters balance. Generally speaking, through the studies of the characters in the current education textbooks and reading materials during the period of $\mathrm{K}$ 12 in China, it is found that the number of males is more than that of females [2]. Therefore, Chinese textbooks can also learn from them and improve the textbooks to keep the number more equal.

\subsubsection{Stereotypes towards Female Existing in the Chinese K-12 Textbooks}

Gender stereotypes are the expectations, requirements, and rigid ideas of men or women in their behaviors, roles, and personality characteristics [5]. The gender stereotype in the textbook is reflected in the image of boys with short hair, sports clothes, mischievous movements about intelligence, while the image of girls with long hair, skirts, timid and movements about housework. The male images in the textbook are mostly social and enterprising, while the female's life field is mostly concentrated in the family. This kind of professional division of labor also reflects the traditional gender stereotype that "men work outside and women work inside".

The female characters always seem to appear ignorant or weak in opposition, especially in scenes in which the male and female characters appear simultaneously [1]. Also, $\mathrm{Yu}$ and $\mathrm{Hu}$ mentioned that the number of women's participation in housework is $100 \%$, while the number of men's participation in housework is $0 \%$ [5]. Besides, of the 49 women in the Chinese language textbook, 32 appear in the family field. Meanwhile, illustrations show that there are obvious gender stereotypes in the behavior characteristics, character images, and role division of male and female children. For example, in a Chinese compulsory education textbook, the boy appeared 24 times, the girl appeared 12 times, especially in a chapter, boys appear 20 times and girls only 5 times. The questions about why were raised by men. On the other hand, women are thought to be affectionate and caring and are given important responsibilities such as caring for the small environment and animals. However, boys are back in the leading roles when it comes to the big themes of human existence, appearing three times more often than girls [5].

As an important element of the education system, textbooks have an imperceptible influence on students' education. This gender stereotype ignores individual differences and restricts and hinders the normal development of human gender cognition. Students, both male and female, may have problems with their own identity if they find themselves different from what they think males and females should look like. As the textbook that they think is always right sets up a fixed and singlegender image of the characters, they may be self-doubt about themselves and think they are strange when they find they do not fit this type. This also leads to students' misconception of gender. For girls, these stereotypes cause their lack of confidence. Girls will have a sense of self-inferiority and agree with the wrong values of sexists. As soon as girls become less confident, they will hesitate on the path of self-realization. For boys, information like "Boys should be strong" will give emotional and sensitive boys mental pressure. Because they think their surrounding environment discourages them from expressing their emotion, they have to bury my anxiety and pain deep inside. Gradually, they may get mental problems and release their stress in abnormal ways. Additionally, these stereotypical characters provide boys a sense of superiority. For example, boys probably think it is not so noble and improper for them to engage in housework, and thus they might have an awareness of resisting participating in housework

To sum up, the existence of gender inequity in Chinese elementary education textbooks is not conducive for students to form a correct concept of gender. If the students always keep accepting the view of male superiority, then the road to the realization of gender equity will be even longer.

\subsection{Family Factors Influence Gender Role Recognition}

The family also has an important impact on children's psychology and gender role recognition. Gender role refers to a set of behaviors corresponding to their gender that people obtain through imitation and learning in the process of socialization. Still, through some parent-child relationships or family, baptism can inhibit the development of one party's gender. There is a difference between gender and sex. "Sex refers to a set of biological attributes in humans and animals. Gender refers to the socially constructed roles, behaviors, expressions and identities of girls, women, boys, men, and gender diverse people" [6]. First of all, family members and their 
relationships are closely related to children's cognition. According to Ding, when children are more cared for and understood by opposite-sex parents, their gender roles will develop in the direction of heterosexuality or androgyny. In contrast, the caring and understanding of same-sex parents can help children form traditional masculine and feminine gender roles [7]. The influence of the combination of both sex parents is the best for children to develop their cognition". Generally speaking, if husband and wife in a family have tense relationships, children living in this environment are prone to anxiety, tension, low self-esteem, and insecurity. This will have extremely adverse effects on children's social adaptation and personality development, and then their gender role as well. From our perspectives, children living in divorced families or children in disharmonious families may have different values, and family relationships may cause them to miss the correct family relationship. They will feel that "this is the right or common state of life," because of the limited things they have come into contact with, like only keep in touch with their mother, but they have no chance to be corrected.

Moreover, parents' educational methods and educational attitudes may also cause children to have negative emotions. As stated by $\mathrm{Yu}$, "related research in psychology has pointed out that parental education methods for their children can be divided into three types, namely (1) democratic or generous; (2) authoritative or arbitrary; (3) indulgent or doting" [8]. The second way of education shows that the parents control all aspects of the child, and the adult must restrict every move of the child. Once a child makes a mistake in something, the parents severely criticize it. Under such educational conditions, children are likely to have serious fears and often lie to avoid punishment. At the same time, children who are often beaten and scolded may become irritable, stubborn, and self-willed. The third way of education shows that parents love their children in every possible way, obey them, and let them develop. It is generally difficult for children who grow up under this kind of education to form a good personality. If the gender character of one side is suppressed, the children are likely to develop the character of the other side to the extreme, which may be gentle or over-emotional. This is important because in today's society, "sissy", which is a word used to describe an effeminate man or boy [9], is being mentioned more and more. Some people think about whether their gender roles are truly correct. But in fact, there is no specific standard. Not all boys should be masculine, and not all girls should live like a princess. Many stereotypes of gender originate from family influences. Due to the influence of family education, some people have gradually deviated from social and cultural standards, and gender consciousness has been weakened, confusing about gender roles. It is possible to prove the hypothesis that the parents might educate children, which can cause this kind of situation.
Last but not least, the family condition can also be a factor that causes gender inequity. According to Yao, family cultural capital mainly refers to the education level of fathers and mothers represented by academic qualifications. The amount of family's cultural capital will affect the most direct factor of children's higher education enrollment opportunities. The more cultural resources of the family, the more opportunities for students to obtain better institutions of higher learning [10]. The reason why I support with this important reason is that this factor largely determines other factors in the family. First of all, parents' occupations are determined by their cultural accomplishments, and different occupations determine their different economic incomes, and in turn, determine the material conditions of the family. Secondly, the cultural accomplishment of parents determines the way parents educate their children and their expectations of children. Parents who have received more education are more aware of the importance of gender equality education for their children. Parents in rural areas or with low education do not pay attention to the education of their children, especially the education of girls. And according to $\mathrm{Yu}$, "if a family's living conditions are superior, they can buy more development materials (such as books, newspapers, intellectual toys, learning machines, etc.) for their children, and they can also take the children out for sightseeing and expand their horizons. Speed up the process of its socialization" [6].

Overall, family members' relationships, parents' educational methods and attitudes, and family living conditions impact children's gender role recognition. These factors will lead to uncorrectable errors.

\subsection{Teacher's Factors}

\subsubsection{Unbalanced Gender Ratio}

With the development of economic, technology, and education, an unbalanced gender ratio in elementary education has become more serious in recent years. According to many studies, the proportion of female teachers is higher than that of male teachers [11-13]. Female teachers in primary schools account for the highest proportion of teachers, accounting for 57.9 percent, while female teachers in junior high school account for 52.1 percent and senior high school teachers account for 49.4 percent [14]. The problem of gender imbalance among primary school teachers is even more severe in secondary or tertiary cities and towns. Studies pointed out that boys suffer more from the influence of imbalance ratio [14]. With female teachers occupies relatively large, boys become less masculine, whose sounds, words and behaviors tend to be feminine. It is like boys nowadays get educated in single parent families, with less guidance from fathers. 


\subsubsection{Teacher's Behavior}

Here are three perspectives to study the behavior of teachers: the content perspective, the methods or pedagogical perspective, the interpersonal perspective [15]. The teacher's behavior discussed below are all the behaviors interacting with students in the elementary period. The study supports that the different behaviors of male/female teachers will indirectly reflect in five basic parts in teaching: lesson preparation, class attendance, assignment and correction, extracurricular tutoring, and academic evaluation [16]. Take the "pearl bird" in the fifth grade textbook as an example. The pearl bird selected by several females in their power-point is small, cute, and needs to be cared for. However, pictures of birds in male teachers' power-point became beautiful, novel, and dynamic to present the pearl birds with a sense of strength and life vitality.[16] According to the study, a teacher's interpersonal behavior is divided into negative interpersonal and positive interpersonal behavior. Students perceived that female teachers scored higher than male teachers in all positive interpersonal behaviors but lower than male teachers in all negative interpersonal behaviors [15]. Students are more likely to receive understanding, support, friendly help, leadership, strict and trust from female teachers, and dissatisfaction, punishment, and differential behavior from male teachers. Compared with male teachers, female teachers have more positive educational concepts in line with modern educational values [17].

\subsubsection{Preferences of Male and Female Teachers}

The difference in teaching can be explained as unconsciousness of gender difference, and studies pointed out that the female teachers will ask the whole class to be as quiet and disciplined as possible. In contrast, male teachers pay more attention to cultivating the students enterprising and innovative characters, which will lead to different results in cultivating students. In the question section, male teachers generally prefer more innovative answers, and female teachers prefer organized answers [16]. Male teachers have more tolerance for naughty students while female students generally prefer calm and highly disciplined students [14].

As a result, different preferences of female and male teachers will affect students' academic performance, passion for study, and formation of characteristics.

\subsection{SOCIAL FACTORS}

Three main social factors can either directly or indirectly lead to gender inequity in higher education. The first factor is gender norms commonly held within people; the second is economic status and family income, and the third is the lack of political support.

\subsubsection{Stereotypes on males and females bring restrictions on certain behaviors on both genders}

According to research done by the World Banks, females are more likely to suffer from maternity harassment in public places because of the lack of law protection. Constant exposure to such depressing phenomena can leave a negative effect on females' mental states. Females become more vulnerable and more sensitive under such conditions. They tend to avoid showing up in public places such as hospitals and schools to protect themselves [18]. In contrast, another article suggests that males usually receive better survival in society; in this way, males can have confidence when they are in public spaces, including schools. This difference in females' and males' metal states leads to a gap in education: males go to school more frequently than females [19]. Society can not only have effects on how people think but also what people do. Gender norm refers to "how [people are] expected to act, speak, dress, groom, and conduct ourselves based upon our assigned sex." [20]. A book suggests that gender norms originate from ancient Greek philosophy and still heavily affect modern society, especially education. Modern education is based on a theory cited and developed by Locke and Russell, and this thought has penetrated every aspect of education of all time. Locke regards that the fundamental purpose of education is to educate males, and females should definitely not be educated. Although Russell does not support Locke's idea, he states that the bias on females is rational. Russell says that the mission of females is to reproduce and to educate their children. In society, females do not have the right to participate in social life. Instead, they should involve through their husbands, and they need to help their husbands always [21]. As a result, gender discrimination exists as females nowadays are still expected to offer assistance to their husbands. A female doesn't have to read and learn too much in their words.

\subsubsection{The Influences of Family Incomes and Financial Returns}

From the economic perspective, family incomes are proportional to the chance that females can receive education, and the financial income of investing in education is also taken into consideration. Research has shown that no matter under which kind of family economic status, men can always have educational opportunities. But for women, only those in relatively high social status can have the chance to accept education. The financial return is also a factor that limits females' education opportunities. The financial return here refers to how much parents can get after they have funded their sons' or daughters' education. Men are considered to have higher financial returns than women, and women are nearly considered as having no financial return. Parents 
always think that sons can bring them more direct financial return as they will take care of their parents when their parents get old. Conversely, daughters will soon get married and have little or no relation with their origin families, which results in the extremely low financial returns of females [22]. These parents educate children and regard them from the investors' perspective, which can get more benefits from investing sons' education rather than that of daughters.

\subsubsection{The Influence of the Lack of Political Protections}

Except for social stereotypes and financial reasons, other factors might influence gender discrimination, which is politics. Females are in unfavorable conditions in the political system, as the lack of female political representatives results in the ignorance of gender inequity. An article points out that laws should have been very objective and fair, but they have less attention to gender inequity. The reason for it is that laws should consider fairness and consider some influences on social norms, which might be written in laws. In this society, males' superiority over females is a well-accepted social norm, so females' rights cannot be protected fully. The idea of gender inequity has penetrated throughout human history so that laws cannot fight against thousands of years of history. The ignorance of politics towards gender inequity potentially favors it and makes it more serious [23]. Moreover, due to the gender norms of what females are expected, females can hardly participate in political activity. This is why there are only a few female political representations. As a result, the gender inequity problem, including education opportunities, will not be mentioned, and thus, modified [18].

\section{CONCLUSION}

This article aims to arouse people's attention to gender inequality in K-12 education and arouse their reflection on these phenomena. The article mainly reviews the reasons for gender inequality in Chinese higher education during the K-12 period from four aspects: textbooks, teachers, family, and society. There are four main findings: (1) the existence of gender inequity in Chinese elementary education textbooks is not conductive for students to form a correct concept of gender; (2) family members' relationships, parents' educational methods and attitudes, and family living conditions have impacts on children's gender role recognition; (3) the self-deny, financial return, lack of political protections for females will influence their chances to education, which causes gender inequity; (4) highly-unbalanced ratio of male and female teachers unconsciously leads to different behaviors of teaching and further influence students being educated. These four aspects mainly affect children's values and their future understandings of gender. These negative aspects will have influences on children's growth. The authors hope to remind parents, teachers, and education-related departments to pay attention to gender education and guidance for children by analyzing cases and data. Sometimes some details will have an indelible impact. Even in many large cities, gender equality education is a serious topic. Many children have left psychological traumas due to their family defects or social condemnation. Many neglected details in education are also the accomplices of these children's negative. Through this review, the authors hope that more families, schools, and educators can be inspired, and thereby children can get better education and understandings of society.

\section{REFERENCES}

[1]Zheng, Y. \& Lu, F. P. (n.d.). Discussion on Gender Inequality in Textbooks of Primary and Secondary Schools in China from the Perspective of Educational Sociology.

[2]Hsü, H. L. (2013, October). A Brief Discussion on the Problem of Gender Inequality in Chinese School Education. Journal of Huanggang Normal University, 33(5).

[3]Wu, T. H. (2018, June). Retrospect and Prospect of Gender Culture Research in Chinese Teaching Materials. Modern Education Science, 6.

[4]Chang, C. C. \& Huo, S. Y. (2016, July). Comparative Research on the Gender Value Orientation of Characters in Chinese and American Primary School Chinese Textbooks. Modem Education Science, 7

[5]Yu, W. \& Hu, J.(2005). Gender inequality in compulsory education in China. Journal of Northeast Normal University (Philosophy and Social Sciences Edition), (5).

[6] What is gender? What is sex? - CIHR. Cihr-irsc.gc.ca. (2021). Retrieved 16 April 2021, from https://cihrirsc.gc.ca/e/48642.html.

[7] Ding, Zhi. (2015). The Influence of Family Education on Children's Gender Roles. Retrieved 27 March 2021, from.

[8] Yu, Yu. (2019). On the Impact of Elementary School Students' Education on Family Factors. Wen Cun Reading Magazine. Retrieved 27 March 2021, from.

[9] Definition of SISSY. Merriam-webster.com. (2021). Retrieved $16 \quad$ April 2021, from https://www.merriam-webster.com/dictionary/sissy.

[10] Yao, M. (2015). Research on the Influence of Family Factors on the Equity of Higher Education Entrance 
Opportunity and Countermeasures. Brand. Retrieved 27 March 2021, from.

[11] Xie K.Z. (2013). AN analysis of gender imbalance among primary education teachers. Company, 365 . The doi: CNKI: SUN: SHNG. 0.2013-13-313

[12] Chang S. (2015) Causes and solutions of gender imbalance among primary school teachers. Jilin Education: Comprehensive,58

[13] Yao, Y.Z. \& Li H.Q. (2017). Study on the change and influence of gender structure of teachers in compulsory education in Ningxia. Ning Social Science.

[14] Li X.W. (2013), Analysis of gender imbalance and countermeasures of gender imbalance in primary school teachers. Science Normal University.

[15] Xiang Q.(2009), The Relationship between Teachers' Interpersonal Behavior, Junior Middle School Students' Self-concept and School Adaptation. Sichuan Normal University.

[16] Liu Y.Q.(2019). A study on the influence of gender imbalance of teachers on primary school students. Electronic Journal of the New Education Era(Teacher's Edition), 179.

[17] Lin Q.Y.(2007). A Study on Teachers' Educational Beliefs and Behaviors in Compulsory Education. Fujian Normal University.

[18] 10 causes of gender inequality. (2020, May 16). Retrieved March 27, 2021, from https://www.humanrightscareers.com/issues/causes -gender-inequality/

[19] Browne, E.\& Millington, K. A.(2015, October 28). Human development and gender inequality. Retrieved March 27, 2021, from https://gsdrc.org/topic-guides/social-developmentand-human-development/human-development-andgender-inequality/

[20] Parenthood, P. (n.d.). Gender identity \& roles: Feminine traits \& Stereotypes. Retrieved April 16, 2021, from https://www.plannedparenthood.org/learn/genderidentity/sex-gender-identity/what-are-gender-rolesand-stereotypes

[21] Joel Spring.(2012).Wheels in the head: educational philosophies of authority, freedom, and culture from confucianism to human rights (5th ed.).

[22] Ghulam, M. (2005, November). Gender Inequality in Education: Impact on Income, Growth and Development. Munich Personal RePEc Archive, 685.
[23] Hsü, H. L. (2013, October). liieh lun wo kuo hsüeh hsiao chiao yü chung ti hsing pieh pu p'ing teng wen t'i [A Brief Discussion on the Problem of Gender Inequality in Chinese School Education]. Journal of Huanggang Normal University, 33(5). 